\title{
Enhancement of fracture strength of cutted plate glass by the application of $\mathrm{SiO}_{2}$ sol-gel coatings
}

\author{
K. Endres, M. Mennig*', M. Amlung, A. Gier, H. Schmidt \\ Institut für Neue Materialien gem. GmbH, Universität des Saarlandes, Im Stadtwald, D 66123 Saarbrücken, Germany
}

\begin{abstract}
The influence of $\mathrm{SiO}_{2}$ sol gel coatings on the bending strength of soda lime plate glass samples has been investigated by 3 point bending and double ring bending strength measurements. The samples were prepared by manual glass cutting and were coated with two different types of $\mathrm{SiO}_{2}$ coating: A TEOS coating (thickness of about $100 \mathrm{~nm}$ ) was obtained from sols synthesized by acid catalysis of tetraethoxysilane and a MTKS coating (thickness of about $1 \mu \mathrm{m}$ ) was obtained from a methyl modified nanoparticulate $\mathrm{SiO}_{2}$ sol. The coatings were applied by dipping and were densified at $500^{\circ} \mathrm{C}$ for $1 \mathrm{~h}$. The fracture strength $\sigma_{0}$ of edge coated plate glass $(60 \times 25 \times 3.8 \mathrm{~mm})$, determined by 3 point bending test (according to EN 843 1), was increased after coating with TEOS from $\sigma_{0}=24 \mathrm{MPa}$ to $40 \mathrm{MPa}$ (67\% increase). The fracture strength increased to $\sigma_{0}=56 \mathrm{MPa}(133 \%$ increase $)$ on applying MTKS or a double coating of TEOS followed by MTKS. The evaluation of these measurements using Weibull statistical analysis resulted in $m$ values of 4.1 and 4.2 for the TEOS and MTKS coating and 3.5 for double coating (uncoated glasses $m=5.7$ ), respectively. These results combined with high resolution secondary electron microscopy investigations led to the conclusion that the strengthening effect of the two different sol gel systems is due to a partial flaw healing and clamping of the crack sides.
\end{abstract}

Keywords: Glass; Bending strength; Sol gel; Scanning electron microscopy

\section{Introduction}

The low practical strength of glass, which is only a fraction of the theoretical value, can be attributed to the presence of microcracks on the surface of the glass [1]. Several investigations have shown [2,3], that especially chemical reactions at the crack tips are important for the crack growth. Tests with silica have indicated, that an increase of the glass strength can be achieved with organic polymer coatings, which can be traced to the prevention of water attack at the crack tips [4]. A doubling of the strength of silica rods could be achieved with the application of 0.2 to $1 \mu \mathrm{m}$ thick $\mathrm{SiO}_{2}$ coatings [5]. The strength of soda lime glass could be increased with $\mathrm{SiO}_{2^{-}}, \mathrm{ZrO}_{2^{-}}$and $\mathrm{SiO}_{2}-\mathrm{ZrO}_{2^{-}}$ coatings with a thickness of $0.2 \mu \mathrm{m}[3,68]$.

Recently, the influence of different $\mathrm{SiO}_{2}$ coatings on the bending fracture strength of predamaged $2 \mathrm{~mm}$ thick float glass surfaces has been investigated systematically [9] and two mechanisms were proposed for the strengthening effect of the sol-gel coatings.

* Corresponding author. Tel.: +49 6819300 394; fax: +49 6819300 223

E mail address: mennig@inm gmbh.de (M. Mennig)
By using a low viscous alkoxide derived sol (TEOS) it was possible to fill-in the micro flaws in the glass surface and to form chemical bonds between the coating and the side walls of the flaws. This leads to a reduction of the flaw size or a blunting of the tips of the cracks. Furthermore it was shown that by a $\mathrm{SiO}_{2}$ coating with thickness in the low $\mu \mathrm{m}$ range, which could be prepared from a methyl modified nanoparticulate sol [10], a clamping of the flaws could be achieved. Both types of coating could increase the bending strength remarkably, depending on the degree of predamaging.

In many practical applications however, defects at the edges limit the fracture strength of plate glass products. It is well known that this can be avoided by time consuming and expensive grinding and polishing of the edges. These edge effects have been excluded from the above cited investigations [2 9] by using the double ring bending test on plate glass or 3 point bending with cylindrical rods, respectively, for strength measurements. Therefore, the aim of this paper was to apply $\mathrm{SiO}_{2}$ coatings, known for their strength increasing capability on plate glass surfaces, to glasses with strongly damaged edges and to investigate to what extend strength increasing effects could be obtained by using the 3 point bending test. 


\section{Experimental}

The glass substrates (plate glass: $60 \times 25 \times 3.8 \mathrm{~mm}$ for 3 point bending test, $100 \times 100 \times 3.8 \mathrm{~mm}$ for double ring bending test) were prepared by manual glass cutting with a diamond cutter using cutting oil and were cleaned by a dishwashing machine $\left(T \quad 70^{\circ} \mathrm{C}, \mathrm{pH} \approx 13\right.$ ) before coating.

Two different coating sols were synthesized according to the reaction flow charts presented in Fig. 1.

The experimental details for the sol synthesis are described elsewhere [9].

The coating, drying and densification processes are similar for the two sol-gel systems. Coatings have been applied by dip coating with a withdrawal speed of $4 \mathrm{~mm} / \mathrm{s}$. Then the substrates were dried at $100^{\circ} \mathrm{C}$ for $30 \mathrm{~min}$, heated with $1 \mathrm{~K} /$ min to $500^{\circ} \mathrm{C}$ and densified at this temperature for $1 \mathrm{~h}$. The coated substrates were cooled down overnight in the furnace. Beside single TEOS and MTKS coatings, a double layer was prepared by the same process. Both coatings were densified with the same process parameters as the single layers. The coating thickness was determined by profilometric measurements after scratching the coating down to the substrate surface.

The measurements of bending strength of uncoated and edge coated plate glass were carried out with 3 point bending test [11] (25 samples) by applying the tension on the scratched side of the samples. To investigate edge effects the bending strength of glass substrates (air side) was also measured by using the double ring test [12] (25 samples, $100 \times 100 \times 3.8 \mathrm{~mm}$ ). To exclude cleaning and annealing effects, the values of bending strength of the coated glasses were compared with that of cleaned uncoated glasses after a temperature treatment of $500^{\circ} \mathrm{C}$ for $1 \mathrm{~h}$. The measured data were evaluated by the use of Weibull statistical analysis [13].
The scratched and broken glass substrates were characterized before and after coating by high resolution scanning electron microscopy (H-SEM) investigations with Jeol scanning microscope (JSM), substrates sputtered with $\mathrm{Au}$ of $10 \mathrm{~nm}$ thickness and imaged with the secondary electron signal excited at a primary beam energy of $10 \mathrm{keV}$ ).

\section{Results}

To define the starting point and to investigate the influence of the edge defects on the bending strength after cutting the samples (sizes according to experimental), $\sigma_{0}$ and the Weibull modulus $m$ were measured by the double ring test and by the 3 point bending test. The double ring test was used because by this method all of the surface flaws are exposed to the applied biaxial tension regardless of flaw orientation whereas with the 3 point bending test, cracks at the edges are taken into account. If the number and the dimension of the cracks at the edges and on the surface of the glasses are identical, the measured values for $\sigma_{0}$ and $m$ are comparable. In order to separate possible effects of the cleaning step and the thermal treatment, necessary for the densification of the coating, from the effect of the coatings themselves, the bending strength of uncoated glass was also measured after cleaning and after thermal treatment at $500^{\circ} \mathrm{C}$ for $1 \mathrm{~h}$. The results are shown in Fig. 2 .

As it can be seen in Fig. 2, the bending strength of the glasses was measured to $171 \pm 16 \mathrm{MPa}$ and the Weibull modulus $m$ to 3.5 by using the double ring test (see experimental). These values are in a good agreement with the data for float glass with a thickness of $3.8 \mathrm{~mm}$ known from the literature [14]. 3 point bending measurements (see Experimental) lead to $\sigma_{0} \quad 24 \pm 1 \mathrm{MPa}(m \quad 7.7)$. It is obvious, that this significant difference is caused by the damage of
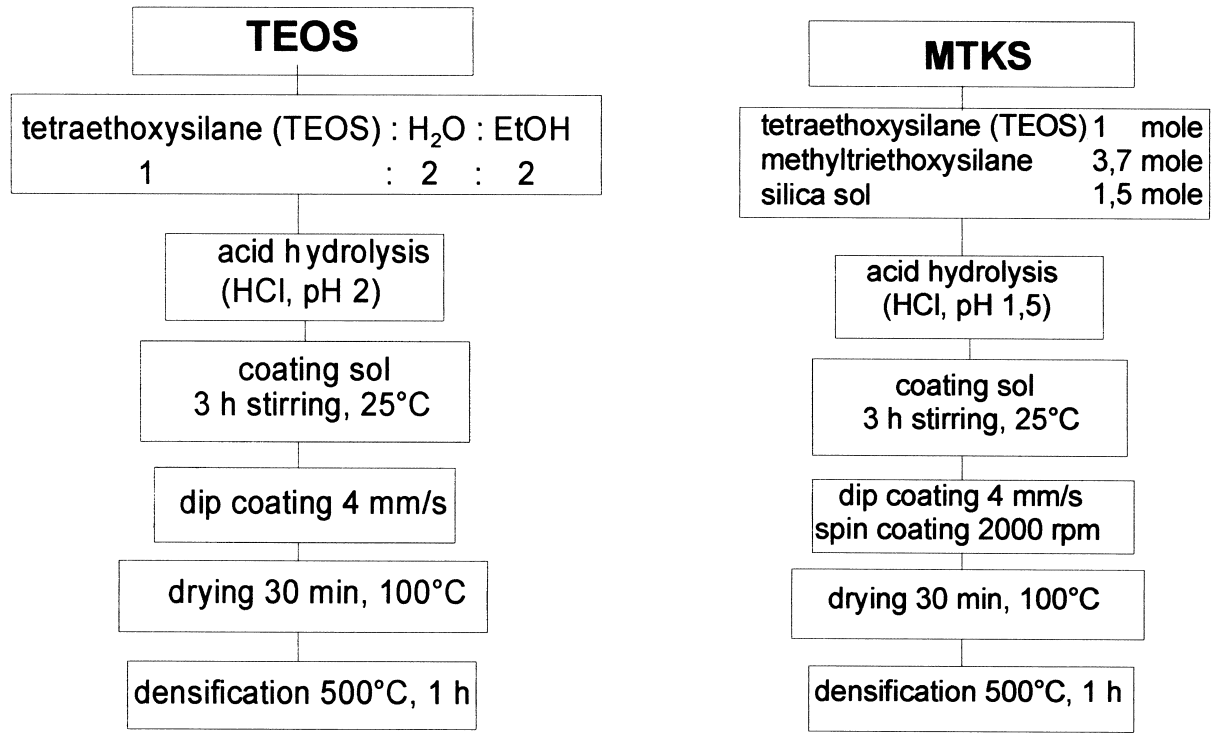

Fig. 1. Synthesis of coatings with TEOS sol, thickness about $0.1 \mu \mathrm{m}$ (left); Synthesis of coatings with MTKS sol, thickness about $1 \mu \mathrm{m}$ (right) [9,10]. 


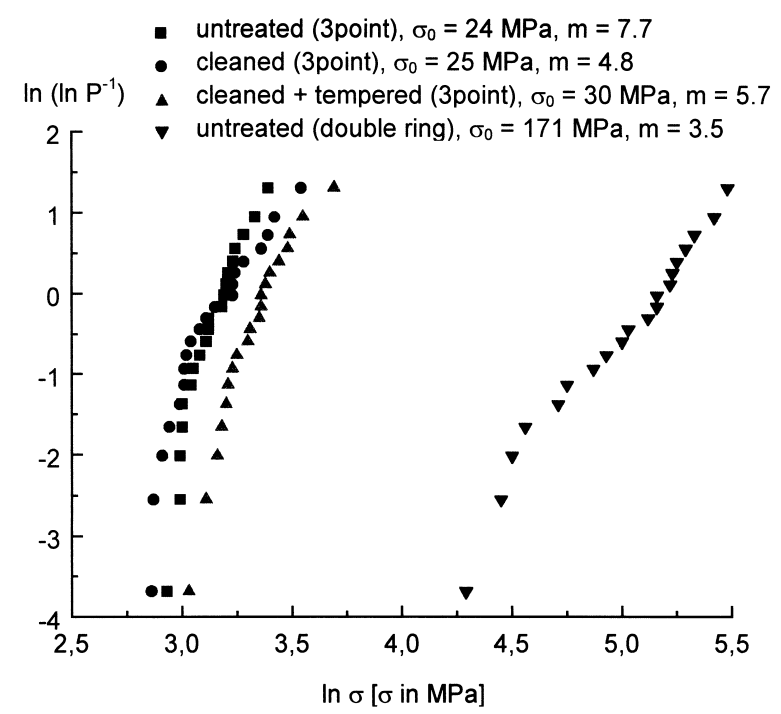

Fig. 2. Bending strength of untreated (double ring test with $100 \times 100 \times 3.8$ $\mathrm{mm}$ samples, 3 point bending test with $60 \times 25 \times 3.8 \mathrm{~mm}$ samples) and pretreated (cleaned in a dishwasher $70^{\circ} \mathrm{C}, \mathrm{pH} 13$, cleaned and heated at $\left.500^{\circ} \mathrm{C}, 1 \mathrm{~h}\right)$ glass.

the glass surface at the edges by the cutting and breaking process. The differences between the two Weibull moduli $m$, obtained by double ring and 3 point bending tests, can be explained by a different distribution of the dimensions of the defects which are responsible for the fracture of the glass [15]. Because of these results, it can be ascertained that the 3 point bending test is really suitable to investigate the influence of edge defects on the bending strength by concentrating the load only to the edges and that defects on the glass plate surfaces are not included under the given experimental conditions. For this reason, further measurements were carried out by using the 3 point bending test only.

After cleaning the uncoated samples, $\sigma_{0}$ changed from $24 \pm 1 \mathrm{MPa}$ to $\sigma_{0} \quad 25 \pm 3 \mathrm{MPa}$ which is not significant and annealing of the cleaned glass sheets for $1 \mathrm{~h}$ at $500^{\circ} \mathrm{C}$ led to a small but significant increase of $\sigma_{0}(30 \pm 2 \mathrm{MPa})$. Compared with the untreated glasses, the $m$ value decreased after cleaning to $m \quad 4.8$ and after the $500^{\circ} \mathrm{C}$ treatment to $m \quad 5.7$ (Fig. 2). These changes are rather small and as one can see from Fig. 2, there is a remarkable deviation of the data from a linear behaviour and therefore differences in $m$ should not be discussed here. The scratched and broken glasses did not show any visible tension in the polarization microscope. Therefore, stress relaxation processes during the high temperature treatment can be excluded in first approximation and the increase in strength measured for the edge damaged tempered $\left(500^{\circ} \mathrm{C}, 1 \mathrm{~h}\right)$ samples can be attributed to the thermal induced formation of new $\mathrm{Si} \mathrm{O} \mathrm{Si}$ bondings leading to a change of the crack geometry.

The Weibull plots of the 3 point bending strength measurements of the coated and uncoated glasses are shown in Fig. 3 and the $\sigma_{0}$ and $m$ values are illustrated in Fig. 4 together with the results obtained for cleaned and thermally treated uncoated glass (Fig. 2) for comparison.

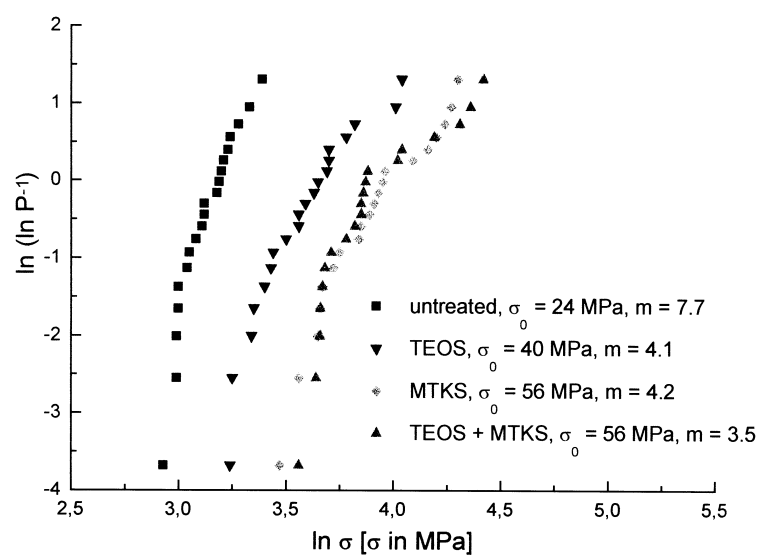

Fig. 3. Bending strength (Weibull plot) of uncoated and edge coated plate glasses (TEOS, MTKS and double layer with TEOS + MTKS, preparation see experimental) by 3 point bending test.

As it can be seen in Figs. 3 and 4, the fracture strength $\sigma_{0}$ of edge coated plate glass was increased by the TEOS coating (thickness $0.1 \mu \mathrm{m}$ ) from $\sigma_{0} \quad 24 \pm 2 \mathrm{MPa}$ to $\sigma_{0}$ $40 \pm 4 \mathrm{MPa}$. With MTKS (thickness $1 \mu \mathrm{m}$ ) the fracture strength increased to $\sigma_{0} \quad 56 \pm 5 \mathrm{MPa}$. In comparison with the uncoated dishwashed $\left(\begin{array}{lll}\sigma_{0} & 25 \pm 3 \mathrm{MPa}\end{array}\right)$ and uncoated dishwashed and $500^{\circ} \mathrm{C}$ tempered $\left(\begin{array}{ll}\sigma_{0} & 30 \pm 2\end{array}\right.$ $\mathrm{MPa}$ ) glasses, the sol-gel coatings show a significant enhancement of the fracture strength.

The strength increasing effect of the TEOS coating can be attributed to the flaw healing ability of this sol [9] which leads to formation of new $\mathrm{Si} \mathrm{O} \mathrm{Si}$-bonds at the crack tips. The interpretation of the Weibull moduli of the edge coated glasses (7.7 before and 4.1 after TEOS coating) is more difficult because already the washing process led to a similar decrease in $m$, as it was shown in Fig. 2 and there is again a remarkable deviation of the Weibull plot from a straight line (Fig. 3).

The nanoparticulate MTKS sol with a coating thickness of about $1 \mu \mathrm{m}$ is also able to increase the bending strength.

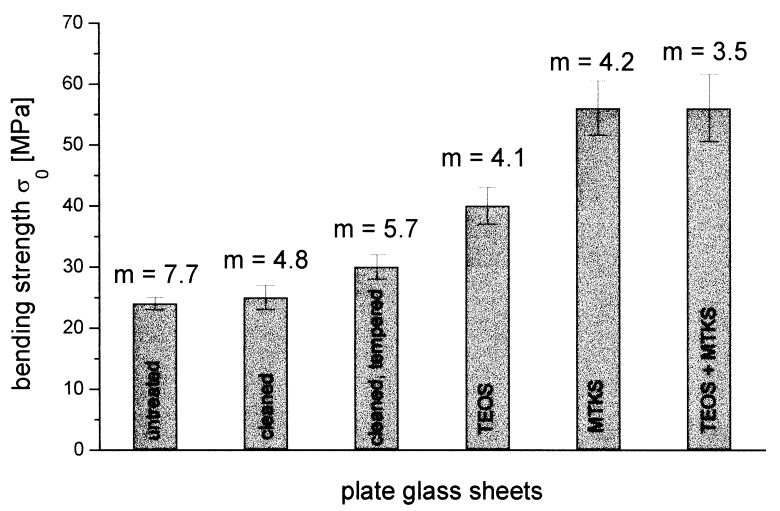

Fig. 4. Bending strength and Weibull parameter of uncoated, uncoated cleaned, uncoated cleaned and annealed and edge coated plate glasses (TEOS, MTKS and double layer with TEOS + MTKS, preparation see experimental) by 3 point bending test. 


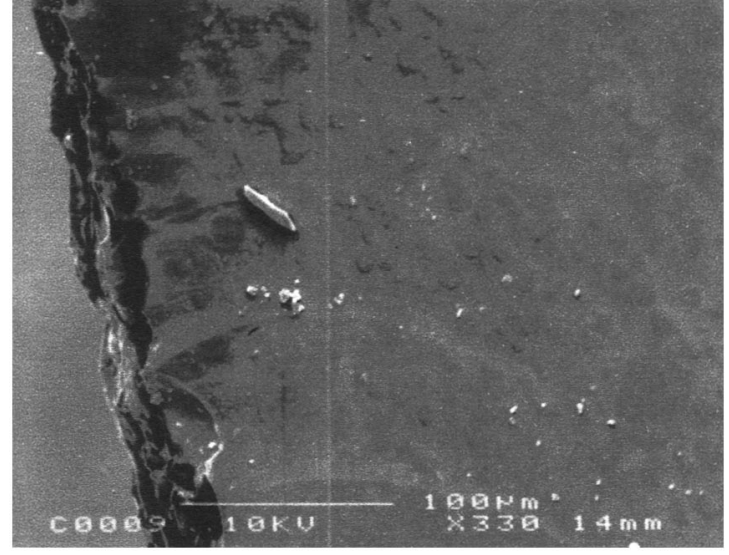

Fig. 5. H SEM photo of an uncoated edge, scratched with a glass cutter and broken (scratched side).

The $\sigma_{0}$-value (56 MPa) exceeded the level of the TEOS sol (40 MPa) and the $m$-value was found to be $m \quad 4.2$. It is assumed that due to the higher coating thickness and the strong adhesion of the MTKS coating to the glass surface [10] the MTKS prevents the growth of the crack by a clamping effect. The effect of the MTKS coating on the Weibull coefficient is the same as in the case of TEOS. After the application of the double coating (TEOS $500^{\circ} \mathrm{C}+$ MTKS $500^{\circ} \mathrm{C}$ ), the bending strength was measured to $56 \pm 5 \mathrm{MPa}$ ( $m$ 3.5), the same value that could be achieved with the MTKS coating alone. Furthermore, Fig. 4 shows that the clamping effect of the MTKS layer is much stronger than the partial flaw healing effect of the TEOS coating. When a 'clamp' breaks at rather high stress, the partially healed flaw cannot withstand, because this protection mechanism is significantly weaker for the given defect sizes and geometry than the clamping effect. This is in agreement with results obtained with the same coating materials on uniformly damaged (Vickers indenter, sand rizzeling) float glass surfaces [9].

The morphology of the edges before and after coating was investigated by H-SEM. The results are shown in Fig. 5.

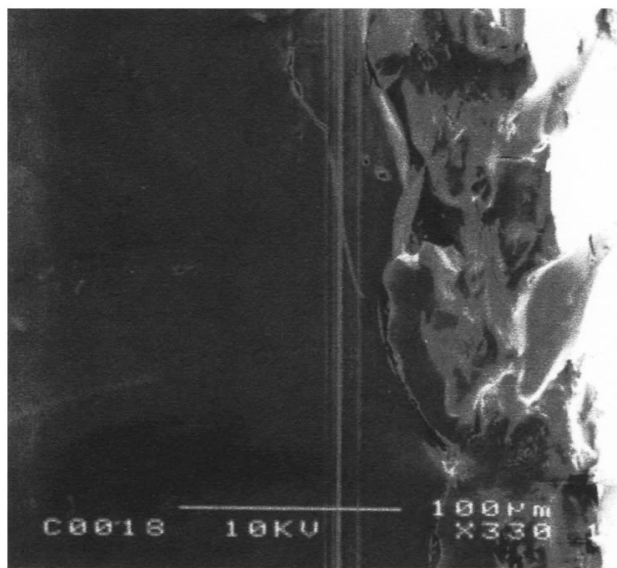

Fig. 6. H SEM photo of a TEOS coated edge (scratched side).

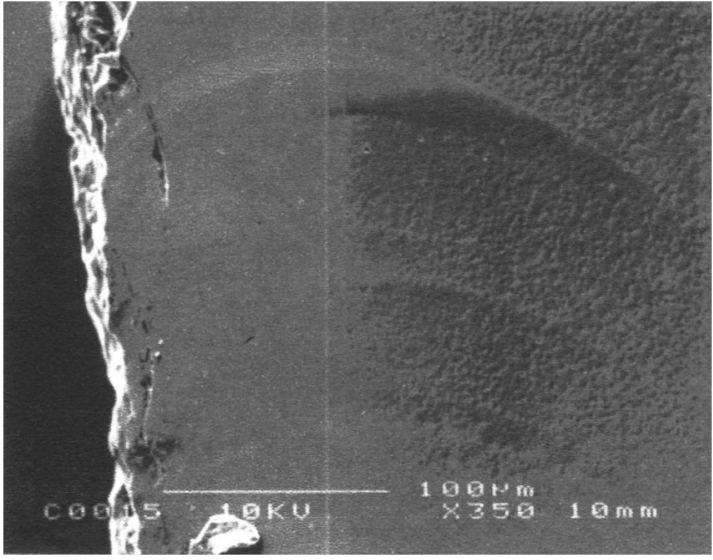

Fig. 7. H SEM photo of a MTKS coated edge (scratched side).

After cutting and breaking the glasses, a strongly damaged area can be seen on the scratched side (see Fig. 5) and Wallner lines [16] are detectable up to a depth of about $400 \mu \mathrm{m}$. The strongly damaged area has a dimension of 30 to $40 \mu \mathrm{m}$ in width and is caused by the diamond cutter. The low bending strength of the glasses can be attributed to these large damages, since it has to be assumed that they are combined with micro flaws. After coating, a distinct smoothing and filling of the damages can be obtained with TEOS (see Fig. 6). The coating covers the edge well, however single cracks can be seen. A filling of the micro flaws cannot be proven by this method, because they are located inside the glass and the crack tips are not visible at the surface. However, the good wetting and covering of the edge can be assumed to be a necessary prerequisite for the flaw healing effect. Furthermore it can be seen that the surface defects are not filled completely by the TEOS coating. In Fig. 7 the edge is shown after coating with MTKS.

As one can see from the pinholes in the MTKS layer, the coating is covering the edge completely. The smoothing effect by filling the large defects is much stronger compared to TEOS (see Fig. 6). Therefore the hypothesised clamping mechanism of this coating is forced.

\section{Conclusion}

The investigations have shown that a nanoparticulate $\mathrm{SiO}_{2}$ sol, which allows the preparation of coatings on glass with thickness in the low $\mu \mathrm{m}$ range is suitable to coat the edges of cutted float glass completely. The coating leads to a remarkable increase in strength, which can be attributed to a clamping of the defects.

However, the strength increase obtained by this edge coating does not reach the level of the strength of the glass surface under the chosen experimental conditions.

Therefore, a comparison with grinded and also with polished edges will be necessary in order to evaluate the practical applicability of the coatings in the future. 


\section{Acknowledgements}

The authors thank the AiF ('Arbeitsgemeinschaft industrieller Forschungsvereinigungen', Köln, AiF-no. 10651) and the HVG ('Hüttentechnische Vereinigung der Deutschen Glasindustrie', Frankfurt/M.) for financial support and the members of the project assisting working group and Prof. Dr. H. A. Schaeffer for their fruitful discussions.

\section{References}

[1] A. Griffith, Philos. Trans. A 221 (1920) 163.

[2] J.S. Jeon, D.H. Jeon, J. Corros. Sol. Soc. Korea 19 (1990) 45.

[3] B.D. Fabes, D.R. Uhlmann, J. Am. Ceram. Soc. 73 (1990) 978.

[4] J.E. Ritter, J. Am. Ceram. Soc. 56 (1973) 402.
[5] T.T. Wang, H.M. Zupko, J. Mater. Sci. 13 (1978) 2241.

[6] P.F. James, M. Chen, F.R. Jones, J. Non Cryst. Solids 155 (1993) 99.

[7] A. Maddalena, M. Guglielmi, A. Raccanelli, P. Colombo, J. Non Cryst. Solids 82 (1986) 461.

[8] B.D. Fabes, W.F. Doyle, B.J.J. Zelinski, L.A. Silvermann, D.R. Uhlmann, J. Non Cryst. Solids 82 (1986) 349.

[9] M. Mennig, K. Endres, M. Amlung, A. Gier, H. Schmidt, Glastech nische Berichteto (1999).

[10] M. Mennig, G. Jonschker, H. Schmidt, in: J.D. Mackenzie (Ed.), SPIE Proc. Sol Gel Opt. II, 1992, p. 125.

[11] EN 843 1, Bestimmung der Biegefestigkeit, (1995).

[12] DIN 52 292, Bestimmung der Biegefestigkeit, (1984).

[13] U. Engel, H. Hübner, J. Mater. Sci. 13 (1978) 2003.

[14] S.T. Gulati, R. Akcakaya, R. Gy, J.R. Varner; Proc. 18th ICG on Glass, San Francisco, 1998, pp. 1621.

[15] W.A. Weibull, J. Appl. Mech. 18 (1951) 293.

[16] V. Caimann, in: Festigkeit von Glas, HVG Fortbildungskurse, Frank furt, 1987, pp. 85149 